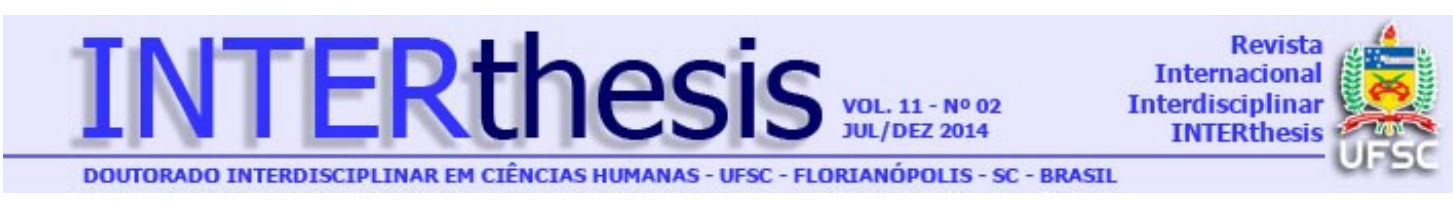

\title{
O MITO DE DON JUAN E A SUBJETIVIDADE MODERNA
}

\section{Resumo:}

Paulo Victor Bezerra ${ }^{1}$ José Sterza Justo ${ }^{2}$

A lendária figura de Don Juan habita o imaginário popular com vivacidade e extensão dignas de um mito, apesar de seu pouco reconhecimento enquanto tal, na literatura científica. O objetivo deste artigo é verificar se Don Juan pode ser entendido como um mito moderno; compreender sua natureza mítica e a sua relação com o homem moderno. Buscamos nos orientar por uma análise estruturalista e histórica de duas obras literárias sobre Don Juan: a escrita por Tirso de Molina, em 1630, e a de Molière, escrita em 1665. As análises realizadas permitem sustentar que Don Juan é um mito tipicamente moderno ao se constituir por narrativas que pinçam, dão forma, concretude e inteligibilidade a um mundo e a um homem nascentes sob os signos do individualismo, da burla da lei, do hedonismo, da arrogância e ousadia, forjados a partir da sexualidade.

Palavras-chave: Mito. Don Juan. Subjetividade. Modernidade. Estruturalismo.

\section{INTRODUÇÃO}

Deveríamos definir o homem como animal symbolicum, não como rationale. (Ernst Cassirer, 2005, p. 12).

A lendária figura de Don Juan, como um homem galã, conquistador e sedutor de mulheres, habita o imaginário popular, ainda que não seja reconhecida com esse nome e nem remetida às obras literárias as quais consagraram e mantiveram esse mito, ao longo do tempo. Sua imagem está profundamente associada a um determinado tipo de personalidade e conduta, a um estilo de pensar e agir virtualmente presente em nós, sendo inúmeras as menções a essa figura como um

\footnotetext{
1 Doutorando em Psicologia pelo Programa de Pós-graduação em Psicologia e Sociedade pela Faculdade de Ciências e Letras da Universidade Estadual Paulista Julio de Mesquita Filho, Assis, SP, Brasil. E-mail: paulusvictorius@gmail.com

2 Doutor em Psicologia Social pela Pontifícia Universidade Católica de São Paulo. Professor da Universidade Estadual Paulista Júlio de Mesquita Filho, Assis, SP, Brasil. E-mail: sterzajusto@yahoo.com.br
}

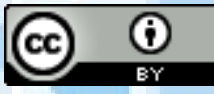
Esta obra foi licenciada com uma Licença Creative Commons - Atribuição 3.0 Não Adaptada. 
mito, como algo que transcende a dramaturgia ou a literatura e se enraíza profundamente na cultura oral.

Embora boa parte dos trabalhos acadêmicos sobre Don Juan se situem no campo da crítica literária, não é incomum encontrarmos escritos sobre um "donjuanismo" também no âmbito da Psiquiatria, das Psicologias e da Filosofia. Seja para enquadrar subjetividades como padrões de desorientação e adoecimento, seja para considerá-la como potencial caminho dos desejos inconscientes ou, então, como uma estilística de existência, a figura de Don Juan é tomada como exemplo paradigmático.

Historicamente, a primeira escrita sobre Don Juan surge em 1630, na pena de um frade dramaturgo, o qual assinava como Tirso de Molina. Não tardou para que essa estória ganhasse projeção e passasse a reencarnar, de tempos em tempos, outras modalidades artísticas. Destarte, a saga de Don Juan foi reescrita por Molière, em 1665; tornou-se "a mais perfeita obra já vista", nos arranjos e na batuta de Mozart (1787); virou poema épico na obra de Byron (1819-24); foi filosofado por Kierkgaard (1843) e poetizado por Baudelaire (1861), além de ter sido retratado em inúmeras pinturas. Ademais, adentrou o cinema através das lentes de Bergman (1960) e foi representada por Brigitte Bardot (1973), até que, mais recentemente, nos foi narrada por José Saramago (2005). Isso, para citar suas recriações mais famosas.

Em nossa Dissertação de Mestrado (BEZERRA, 2011), trabalhamos com a ideia de que esse tema, dada sua notável envergadura, é uma excelente forma de análise das transformações que tomaram curso na subjetividade moderna. Nossa hipótese encontrou boa ressonância, na medida em que observamos que as releituras desse enredo se configuram, na verdade, como atualizações. Entre outras coisas, pudemos concluir que, a despeito de haver um reposicionamento de algumas instituições de acordo com o período em que a estória foi reeditada, há uma problemática central a qual se mantém praticamente inalterada.

Neste artigo, pretendemos expor e analisar o núcleo fundamental - o plot em torno do qual tantas releituras e atualizações foram possíveis. Com isso, acreditamos poder traçar um percurso dessa figura e de seu correspondente modo de subjetivação que emergem com a nascente modernidade, no século XVI, e se prolongam, com modificações, até os dias atuais.

R. Inter. Interdisc. INTERthesis, Florianópolis, v.11, n.2, p.72-95, Jul-Dez. 2014
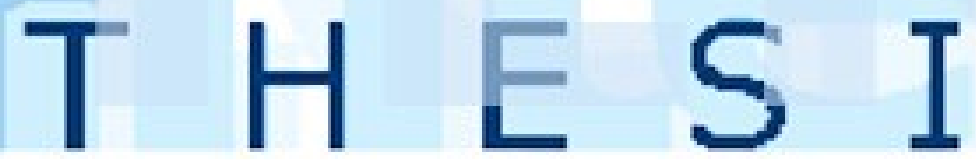


\section{O LUGAR DA MITOLOGIA NA MODERNIDADE E O DE DON JUAN NA MITOLOGIA}

Embora o conhecimento moderno tenha fortalecido sobremaneira a modalidade racional de entendimento do mundo e do próprio homem, grandes correntes da Psicologia demonstraram a pujança e, por vezes, a primazia do pensamento mítico em orientar nossa relação com o mundo. Nesse sentido, é evidente que as descobertas de Freud e de seus colaboradores acerca da existência e do modo de funcionamento do inconsciente contribuíram significativamente para as Ciências Humanas como um todo, pois tais estudos reorientaram o foco da racionalidade para as fabulações que regem os alicerces do funcionamento mental.

De acordo com Vernant (2010), seria mais justo afirmar que tais pesquisadores, passado o afã modernista de crença absoluta na racionalidade científico-positivista, redescobriram a natureza mítica do ser humano, uma vez que essa observação já havia sido feita por Aristóteles. Na perspectiva do filosofo grego, "o mito seria uma espécie de esboço do discurso racional: através de suas fábulas, perceber-se-ia o primeiro balbucio do logos" (VERNANT, 2010 p.188).

Quando aprofundamos o estudo nessa área de conhecimento, percebemos que os clássicos e as mitologias de diversas etnias já foram alvo de inúmeras análises míticas, as quais culminaram, inclusive, em grandes controvérsias, como é o caso de Édipo. Diferentemente desses, Don Juan, Fausto, Hamlet, Madame Bovary e tantos outros são tomados como figuras paradigmáticas de certos modos de subjetivação de determinadas culturas e tempos específicos, no entanto, sem a profundidade temporal, nem a abrangência espacial e a viscosidade psíquica e social que a oralidade dos mitos possuía, inclusive, impregnando de tal forma o imaginário coletivo que tornava todos seus autores e transmissores dos saberes que portavam.

Interpelar a personagem e a história de Don Juan, escrita por Tirso de Molina, para além de seu tempo e do contexto específico no qual foi produzida e projetá-la no tempo, captando as nuances e versões que vai adquirindo, é tentar apreendê-la em seu caráter mítico, a saber, como expressão e produção do imaginário coletivo, em transformação.

R. Inter. Interdisc. INTERthesis, Florianópolis, v.11, n.2, p.72-95, Jul-Dez. 2014
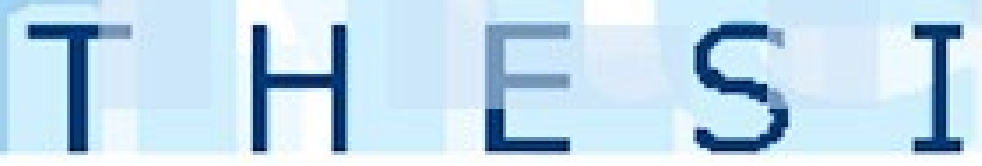
Evocando o exemplo da mitologia grega, temos em Hesíodo um importante porta-voz do panteão de sua cultura. Recorremos a ele, como fonte segura para adentrar o universo do pensamento grego, sem tomá-lo como o criador dessa mitologia. Ainda que seu texto seja adotado como referência, busca-se contemplar, não as palavras de Hesíodo, mas a luz própria dos personagens e enredos ali descritos.

Ernst Cassirer (2003) explica a passagem que confere vida própria às palavras, transmutando um mero sinal gráfico em símbolo. Ele nos mostra que inicialmente concebemos a palavra amalgamada àquilo que ela pretende referenciar. $\mathrm{Na}$ medida em que utilizamos esse sinal sonoro na ausência do objeto sensível referenciado, a palavra carrega consigo uma ilusão de poder materializar o objeto novamente.

Posteriormente, acrescenta o referido autor, compreendemos que a representação sonora não tem o poder de fazer o objeto reaparecer, mas tem o poder de evocar uma ideia em nosso pensamento. Assim, a palavra deixa de referirse somente a um objeto concreto e adquire a dimensão de conceito (CASSIRER, 2003).

Este é o olhar que direcionamos ao objeto deste artigo. Partimos do texto de Molina, situado em seu tempo, para compreender quais aspectos subjetivos do homem ele atinge. Podemos compreender Don Juan oscilando entre a fronteira da palavra com a coisa, nesse sistema apresentado por Cassirer. Se, por um lado, o donjuanismo já é considerado um conceito, já que seu nome é capaz de acender concepções em nosso pensar, por outro, ainda se encontra ligado diretamente a um objeto material e a um tempo determinado, por exemplo, é identificado como o enredo de uma produção imponente, escrita no ano de 1630, por Tirso de Molina.

Nesse caso, entretanto, entendemos que a obra ganhou tal projeção e ressonância desde a sua origem, porque ela toca em algo visceral e durável, com lugar garantido nas produções subjetivas do homem moderno. Afinal, dentre a vastíssima produção simbólica a que temos acesso, todos os dias, por que é que algumas poucas ganham tal destaque e se universalizam, enquanto a massiva maioria permanece datada e confinada aos seus ambientes originais, quando não se evaporam rapidamente?

R. Inter. Interdisc. INTERthesis, Florianópolis, v.11, n.2, p.72-95, Jul-Dez. 2014
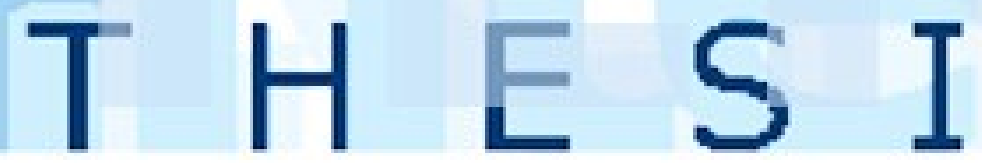
Enquanto o discurso do logos pretende explicar e confirmar a verdade do objeto, a partir de manobras linguísticas, o mythos é, ao contrário, explicado e provado pela existência do objeto. Como exemplifica Mircea Eliade (2010, p. 12), “o mito cosmogônico é verdadeiro porque a existência do mundo está aí para prová-lo; o mito da origem da morte é igualmente verdadeiro porque é provado pela mortalidade do homem, e assim por diante". De forma análoga, a energia da obra de Molina não é a responsável por implantar desejos donjuanescos na sociedade ocidental, mas, ao contrário, é seu poder de invocar figuras e modelos de subjetivação dos modernos, com suas reminiscências arcaicas, que faz essa obra flamejar.

Encontramos duas dimensões epistêmicas acerca da origem dos mitos. Por um lado, entende-se que constituem a expressão de práticas sociais ou linguísticas cristalizadas em um símbolo, por outro, ancorada na tradição platônica e kantiana, há a concepção de que as fabulações míticas são desdobramentos intelectuais de uma essência espiritual (CASSIRER, 2003; VERNANT, 2010; ELIADE, 2010). Como consequência disso, há uma considerável ramificação de definições e metodologias de análise.

Seja tomado como transcendental, seja como puramente material, é consenso que o pensamento mitológico apresenta-se hoje como uma dimensão irrecusável da experiência humana. Lévi-Strauss (2008, p. 248) "pede licença" para utilizar uma curiosa metáfora: "[...] o mito é um ser verbal que, no campo da fala, ocupa um lugar comparável ao que cabe ao cristal no mundo da matéria física”. Embarcando nessa metáfora, podemos admitir que o mito revelaria certa geometria sagrada do pensamento, independentemente de sua procedência; seu conhecimento é "sentido como um desafio lançado à inteligência cientifica, a quem se deve o realce e a compreensão desse outro que é o mito, e sua incorporação ao saber antropológico" (VERNANT, 2010, p. 200).

Em nosso caso específico, como estamos buscando compreender e fundamentar um mito moderno, uma questão se coloca: se tomarmos Don Juan como o condensado de uma determinada relação social bastante situada geográfica e historicamente, reduziríamos sua universalidade e, portanto, seu potencial mítico. Por outro lado, se o tomássemos como algo transcendente ou como o reflexo de uma potencialidade humana natural, estariamos diminuindo seu potencial e até mesmo negligenciando seu caráter moderno.

R. Inter. Interdisc. INTERthesis, Florianópolis, v.11, n.2, p.72-95, Jul-Dez. 2014
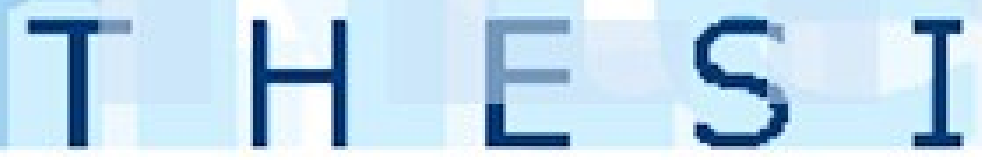
Ao longo de nossas leituras, notamos que esse mesmo impasse foi objeto de estudo de Paul Ricoeur (1970). Preocupado com a aparente crueza da antropologia estrutural e de sua inclinação para abolir a história, esse filósofo esclarece que não recebemos a tradição como um pacote fechado, o qual passa de mão em mão, sem que ninguém o abra, porque "toda tradição vive graças à interpretação" (RICOEUR, 1970, p. 27). Quer dizer, um mito está conectado tanto à história de um povo quanto ao espírito de cada um de seus indivíduos, seja ele pressuposto como transcendental ou linguístico, mantendo uma relação circular entre ambos. O autor argumenta que o limite do estruturalismo foi não colocar em questão a unidade do pensamento mítico, mas pressupor que toda mítica é do tipo totêmica (RICOEUR, 1970).

Em nossa sociedade, prevalece um tipo de pensamento mitológico diferente do pensamento totêmico. Aqui, o essencial não foi decidido durante a criação do mundo, mas depois (ELIADE, 2010; RICOEUR, 1970; VERNANT, 2010). A mitologia contemporânea é toda construída em torno de um tempo mítico distinto do tempo cosmogônico; trata-se de um "tempo histórico, em que o divino e o humano se entrecruzam produzindo um acontecimento que passa a organizar, daí em diante, a existência de certo aspecto da vida" (ELIADE, p. 98).

Tanto Eliade (2010) quanto Ricoeur (1970) evidenciam que a mítica indoeuropeia, proto-helênica e semítica, na qual estamos inseridos, organiza suas transmissões muito menos na reencenação ritualística do que no recontar e na esperança de um novo acontecimento que transforma a ordem. Eliade (2010, p. 102) escreve que os tempos modernos reeditam a mitologia cosmogônica, conferindo à "Entidade Sobrenatural Homem o seu papel de criador da sociedade e do modo de funcionamento atual do mundo". Mais do que isso, esse autor salienta que foi devido ao surgimento da mitologia histórica do Judeu-Cristianismo e seu desenvolvimento em Hegel e seus sucessores que se desbancou a forma mais arcaica de mitologia, que "sobrevive, porém, [...] perfeitamente camuflada na historiografia!" (ELIADE, 2010, p. 102).

Interessante notar que o aspecto histórico de Don Juan ainda é alvo de muitos debates. Há controvérsias quanto à autoria, mas principalmente existe uma vontade de buscar uma existência humana que tenha dado suporte ao personagem mítico. Marañon (1967), por exemplo, defende que o personagem e até mesmo sua saga tiveram inspiração na vida de Conde de Villamediana, um nobre 
contemporâneo de Molina. Nomes ainda como o de Don Miguel de Mañara e Giacomo Casanova são, aleatoriamente, associados à criação do personagem. No entanto, a peça de Molina foi encenada ainda na infância, tanto de Villamediana quanto de Mañara, e Casanova nasceria somente um século depois, em 1725, na cidade de Veneza (SAENZ-ALONSO, 1969, p. 250). Isso apenas "atesta uma forte demanda no sentido de conferir 'realidade histórica' ao mito" (RIBEIRO, 1988, p. 12). $\mathrm{E}$, se historicizar é um dispositivo fundamental do pensamento mítico contemporâneo, vemos aqui mais um argumento em favor do mito.

Fundamentados nessas exposições, afirmamos definitivamente que Don Juan é um mito moderno, de modo que, se inicialmente fora alçado a essa categoria pela percepção popular, também encontramos respaldo na literatura acadêmica para conferir-lhe tal status. Seu enredo congrega os elementos necessários para isso, uma vez que retrata o entrecruzamento entre os planos humano e divino, para a produção de consequências exemplares. Como já demonstramos em nossa Dissertação de Mestrado (BEZERRA, 2011), a peça original foi construída com o propósito máximo de organizar a conduta de certos aspectos do comportamento, que, naquela ocasião histórica, se tornavam preocupantes e problemáticos. Além disso, o reconhecimento posterior reflete a grandeza simbólica e sua distinta capacidade de funcionar como órgão de inteligibilidade e definição de certo aspecto do homem.

\section{METODOLOGIA}

Conforme indicado no início, o mito de Don Juan possui inúmeras releituras e atualizações. Longe de tomar as releituras como algo que possa prejudicar a análise de qualquer mito, Lévi-Strauss (2008, p. 247) esclarece que "a repetição possui uma função própria, que é a de tornar manifesta a estrutura do mito". Dessa forma, até para não cairmos nas peculiaridades de uma ou outra versão, optamos por trabalhar neste artigo com as duas primeiras sistematizações do mito: a original de Tirso de Molina, datada de 1630, e aquela imediatamente posterior, a versão de Molière, de 1665.

No que diz respeito à análise mitológica desenvolvida, buscamos nos orientar através de duas metodologias complementares. Primeiramente, submetemos o mito

R. Inter. Interdisc. INTERthesis, Florianópolis, v.11, n.2, p.72-95, Jul-Dez. 2014
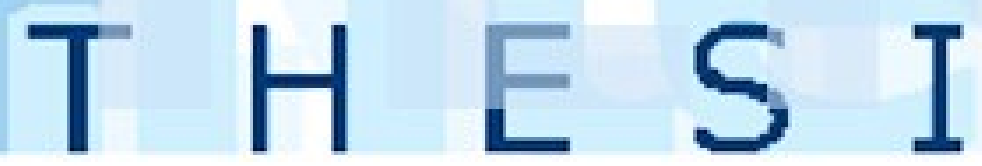
de Don Juan a uma análise estruturalista e, posteriormente, combinamo-la com a análise histórica e hermenêutica, fazendo as pontes necessárias entre outros conhecimentos, a fim de apresentar as possibilidades de sentidos que o mito produz. Elegemos esse caminho por entender que é um meio seguro, bastante defendido na academia, e porque, apesar de propor uma estrutura, a análise só pode ser construída a partir do encontro entre a inteligência analítica e o material analisado (RICOEUR, 1970). O sentido da estrutura é obtido atribuindo-se uma interpretação específica ao conjunto de elementos e à ordenação. As estruturas identificadas e descritas devem ser capazes de autorizar o lançamento de novas hipóteses e de predições.

Procedemos à análise estrutural do mito, seguindo as indicações de LéviStrauss (2008), quando escreve:

Cada mito é analisado independentemente, buscando-se traduzir a sucessão dos acontecimentos por meio de frases o mais curtas possível. Cada frase é inscrita numa ficha que leva o número correspondente à sua posição no relato. Percebe-se que cada carta consiste na atribuição de um predicado a um sujeito. Em outras palavras, cada grande unidade constitutiva tem a natureza de uma relação. (p. 226-227).

Isolamos essas unidades constitutivas em duas tabelas (tabela 1 e tabela 2), onde o eixo orientado da esquerda para a direita e de cima para baixo segue a ordem cronológica na qual os elementos apareceram; é o que o estruturalismo compreende por ordem diacrônica. Já os eixos verticais e as possíveis diagonais seguem aquilo que Strauss denomina ordem sincrônica, ou seja, não dependem dos acontecimentos anteriores, mas se ligam "aleatoriamente" para formar os sentidos do mito.

Levando em consideração o contexto cultural no qual o mito foi primeiro sistematizado e os sentidos que dali emergem, buscamos situar a que parcela da subjetividade humana seu tema remete.

R. Inter. Interdisc. INTERthesis, Florianópolis, v.11, n.2, p.72-95, Jul-Dez. 2014
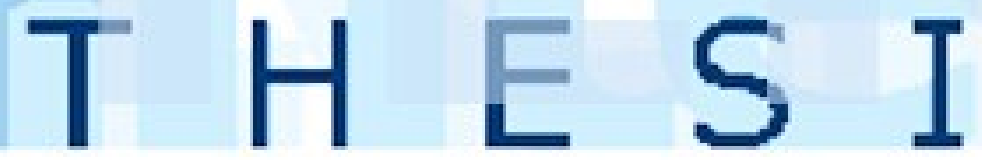


\section{ANÁLISE}

Tabela 1: Estrutura do mito de Don Juan (Tirso de Molina).

\begin{tabular}{|c|c|c|c|c|c|c|c|}
\hline & $A$ & $B$ & $\mathrm{C}$ & $\mathrm{D}$ & $E$ & $F$ & $\mathrm{G}$ \\
\hline a & $\begin{array}{l}\text { D. J. } \\
\text { burla } \\
\text { Isabela } \\
\text { que } \\
\text { fornicari } \\
\text { a } \\
\text { Otávio. }\end{array}$ & $\begin{array}{l}\text { O Tio de D. } \\
\text { J. deixa-o } \\
\text { escapar e } \\
\text { culpa } \\
\text { Otávio. }\end{array}$ & $\begin{array}{l}\text { D. J. e } \\
\text { Cagarolão } \\
\text { naufragam } \\
\text { numa vila de } \\
\text { pescadores. }\end{array}$ & $\begin{array}{l}\text { Tisbea } \\
\text { renega } \\
\text { Anfriso por } \\
\text { ser pobre, } \\
\text { se } \\
\text { interessa } \\
\text { por D. J. } \\
\text { por ser } \\
\text { nobre. }\end{array}$ & $\begin{array}{l}\text { Don } \\
\text { Gonzalo } \\
\text { aceita } \\
\text { casar sua } \\
\text { filha com } \\
\text { D. J. }\end{array}$ & $\begin{array}{l}\text { Cagarolão } \\
\text { avisa D. J. } \\
\text { sobre a } \\
\text { punição com } \\
\text { a morte. } \\
\text { D. J. } \\
\text { responde: } \\
\text { Que tanto } \\
\text { que me fiais? }\end{array}$ & $\begin{array}{l}\text { Tisbea } \\
\text { adverte que } \\
\text { há Deus e } \\
\text { que há } \\
\text { morte. D. J. } \\
\text { responde: } \\
\text { Que tanto } \\
\text { me fiais? }\end{array}$ \\
\hline$b$ & $\begin{array}{l}\text { Don } \\
\text { Juan } \\
\text { burla } \\
\text { Tisbea. }\end{array}$ & $\begin{array}{l}\text { Otávio } \\
\text { reclama } \\
\text { seu } \\
\text { prejuízo e } \\
\text { ganha } \\
\text { terras e a } \\
\text { filha de } \\
\text { Don } \\
\text { Gonzalo. }\end{array}$ & $\begin{array}{l}\text { D. J. e } \\
\text { Cagarolão } \\
\text { voltam a } \\
\text { Sevilha. }\end{array}$ & $\begin{array}{l}\text { D. J. } \\
\text { encontra-se } \\
\text { com seu } \\
\text { amigo Da } \\
\text { Mota e } \\
\text { falam de } \\
\text { suas vidas } \\
\text { de luxúria. }\end{array}$ & $\begin{array}{l}\text { A filha de } \\
\text { Gonzalo, } \\
\text { Dona } \\
\text { Ana, } \\
\text { marca um } \\
\text { encontro } \\
\text { com Da } \\
\text { Mota, seu } \\
\text { primo } \\
\text { amado. }\end{array}$ & $\begin{array}{l}\text { Cagarolão } \\
\text { avisa Don } \\
\text { Juan e o } \\
\text { burlador } \\
\text { terminará } \\
\text { pagando os } \\
\text { pecados. }\end{array}$ & $\begin{array}{l}\text { O pai de D. } \\
\text { J. reclama } \\
\text { suas } \\
\text { desonras e } \\
\text { diz que } \\
\text { Deus é juiz } \\
\text { forte. } \\
\text { D. J. } \\
\text { Responde: } \\
\text { Que tanto } \\
\text { me fiais? }\end{array}$ \\
\hline C & $\begin{array}{l}\text { D. J. } \\
\text { engana } \\
\text { Da Mota } \\
\text { e tenta } \\
\text { burlar D. } \\
\text { Ana } \\
\text { (mas diz } \\
\text { que } \\
\text { burlou). }\end{array}$ & $\begin{array}{l}\text { Don } \\
\text { Gonzalo } \\
\text { reclama a } \\
\text { honra de } \\
\text { sua filha e } \\
\text { duela com } \\
\text { D. J. }\end{array}$ & & & & & \\
\hline $\mathrm{d}$ & $\begin{array}{l}\text { D. J. } \\
\text { mata } \\
\text { Gonzalo } \\
\text { no duelo } \\
\text { e perde. } \\
\text { A culpa } \\
\text { fica com } \\
\text { Da Mota }\end{array}$ & & $\begin{array}{l}\text { Fugindo, D. } \\
\text { J. e } \\
\text { Cagarolão } \\
\text { param numa } \\
\text { aldeia onde } \\
\text { está havendo } \\
\text { um } \\
\text { casamento. }\end{array}$ & $\begin{array}{l}\text { D. J. } \\
\text { aproveita- } \\
\text { se de sua } \\
\text { nobreza } \\
\text { para } \\
\text { sentar-se } \\
\text { ao lado da } \\
\text { noiva. }\end{array}$ & $\begin{array}{l}\text { D. J. } \\
\text { engana o } \\
\text { noivo e a } \\
\text { noiva e a } \\
\text { faz casar- } \\
\text { se com } \\
\text { ele. }\end{array}$ & $\begin{array}{l}\text { Cagarolão } \\
\text { avisa D. J. } \\
\text { que há Deus } \\
\text { e há a } \\
\text { justiça. } \\
\text { D. J. } \\
\text { responde: } \\
\text { Tem meu pai } \\
\text { da justiça a } \\
\text { senhoria e } \\
\text { privança com } \\
\text { el-rei: que } \\
\text { temes? }\end{array}$ & $\begin{array}{l}\text { Aminta, a } \\
\text { noiva, faz } \\
\text { D. J. jurar } \\
\text { por Deus. } \\
\text { Ele } \\
\text { responde } \\
\text { que lhe dê } \\
\text { morte um } \\
\text { homem } \\
\text { (morto), se } \\
\text { acaso faltar } \\
\text { com a } \\
\text { palavra. }\end{array}$ \\
\hline $\mathrm{e}$ & $\begin{array}{l}\text { D. J. } \\
\text { burla } \\
\text { Aminta. }\end{array}$ & $\begin{array}{l}\text { D. J. se } \\
\text { depara com } \\
\text { a estátua } \\
\text { de D. } \\
\text { Gonzalo, } \\
\text { que traz } \\
\text { uma } \\
\text { legenda de } \\
\text { vingança. } \\
\text { D. J. } \\
\text { convida-a a } \\
\text { jantar. }\end{array}$ & $\begin{array}{l}\text { A estátua } \\
\text { vem jantar. }\end{array}$ & $\begin{array}{l}\text { A estátua } \\
\text { pede a mão } \\
\text { de D. J. } \\
\text { como } \\
\text { marca do } \\
\text { compromis } \\
\text { so de que } \\
\text { ele irá } \\
\text { jantar no } \\
\text { mausoléu } \\
\text { no dia } \\
\text { seguinte. }\end{array}$ & $\begin{array}{l}\text { Isabela e } \\
\text { Otávio; } \\
\text { Tisbea e } \\
\text { Gasseno; } \\
\text { Aminta e } \\
\text { Batrício } \\
\text { vão ao rei } \\
\text { reivindicar } \\
\text { suas } \\
\text { honras. }\end{array}$ & & $\begin{array}{l}\text { Don } \\
\text { Gonzalo } \\
\text { anuncia a } \\
\text { justiça de } \\
\text { Deus: } \\
\text { quem tal } \\
\text { faça que tal } \\
\text { pague. }\end{array}$ \\
\hline
\end{tabular}

R. Inter. Interdisc. INTERthesis, Florianópolis, v.11, n.2, p.72-95, Jul-Dez. 2014

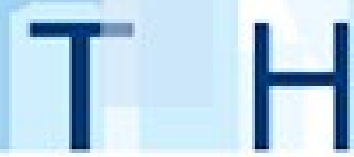




\begin{tabular}{|l|l|l|l|l|l|l|}
\hline $\mathrm{f}$ & Don & Otávio se & O Rei ordena & & & \\
& Gonzalo & casa com & que o cortejo & & & \\
& pede a & Isabela; Da & fúnebre vá & & & \\
mão de & Mota com & até Madrid & & & \\
D. J. e & Dona Ana e & para grande & & & \\
& leva-o & Batrício & reconhecime & & & \\
para o & com & nto. & & & \\
& inferno. & Aminta. & & & \\
\hline
\end{tabular}

Tabela 2: Estrutura do mito de Don Juan (Molière).

\begin{tabular}{|c|c|c|c|c|c|}
\hline & A & $B$ & C & $D$ & $E$ \\
\hline$a$ & $\begin{array}{l}\text { D. J. } \\
\text { sequestra } \\
\text { Elvira do } \\
\text { convento e } \\
\text { casa-se com } \\
\text { ela. }\end{array}$ & $\begin{array}{l}\text { D.J. abandona } \\
\text { Elvira }\end{array}$ & $\begin{array}{l}\text { O criado de Elvira } \\
\text { vem reclamar sua } \\
\text { honra. }\end{array}$ & $\begin{array}{l}\text { D. J. anuncia } \\
\text { que tem novo } \\
\text { amor. }\end{array}$ & $\begin{array}{l}\text { Leporelo alerta } \\
\text { D.J.. - que uma } \\
\text { má vida conduz a } \\
\text { uma má morte. }\end{array}$ \\
\hline$b$ & $\begin{array}{l}\text { Leporelo } \\
\text { lembra a D. J. } \\
\text { que ele matou } \\
\text { um } \\
\text { Comendador. }\end{array}$ & $\begin{array}{l}\text { (Parece, que a } \\
\text { justiça o } \\
\text { absolveu da } \\
\text { morte do } \\
\text { Comendador) }\end{array}$ & $\begin{array}{l}\text { Elvira amaldiçoa } \\
\text { D. J. tanto com o } \\
\text { castigo do céu } \\
\text { quanto com o "ódio } \\
\text { de uma mulher } \\
\text { ofendida" }\end{array}$ & $\begin{array}{l}\text { D.J. e Leporelo } \\
\text { pegam um } \\
\text { barco para } \\
\text { armar uma } \\
\text { burla. }\end{array}$ & $\begin{array}{l}\text { D. J. e Leporelo e } \\
\text { naufragam. }\end{array}$ \\
\hline C & $\begin{array}{l}\text { D. J. tenta } \\
\text { burlar Carlota, } \\
\text { noiva de } \\
\text { Pierrô, um } \\
\text { pescador. }\end{array}$ & $\begin{array}{l}\text { Vestem-se de } \\
\text { mulher para } \\
\text { despistar.- }\end{array}$ & $\begin{array}{l}\text { Os irmãos de Elvira } \\
\text { vêm cobrar suas } \\
\text { honras e } \\
\text { reivindicam um } \\
\text { duelo. }\end{array}$ & $\begin{array}{l}\text { D. J. defende } \\
\text { um homem que } \\
\text { está sendo } \\
\text { atacado por } \\
\text { três. }\end{array}$ & $\begin{array}{l}\text { D. J. ganha } \\
\text { trégua de um dia, } \\
\text { porque o homem } \\
\text { que ajudou (sem } \\
\text { saber) é um dos } \\
\text { irmãos de Elvira. }\end{array}$ \\
\hline $\mathrm{d}$ & $\begin{array}{l}\text { D. J. tenta } \\
\text { fazer um } \\
\text { mendigo } \\
\text { blasfemar em } \\
\text { troca de uma } \\
\text { moeda. }\end{array}$ & $\begin{array}{l}\text { Deparam-se } \\
\text { com o mausoléu } \\
\text { do Comendador } \\
\text { e entram. }\end{array}$ & & $\begin{array}{l}\text { Convidam, } \\
\text { ironicamente, a } \\
\text { estátua para } \\
\text { jantar. }\end{array}$ & $\begin{array}{l}\text { A estátua aceita o } \\
\text { convite para } \\
\text { jantar. }\end{array}$ \\
\hline e & $\begin{array}{l}\text { D. J. consegue } \\
\text { adiar o } \\
\text { pagamento ao } \\
\text { seu credor, Sr. } \\
\text { Domingos. }\end{array}$ & & $\begin{array}{l}\text { O pai de D. J. e } \\
\text { Elvira pedem que } \\
\text { ele mude de } \\
\text { atitude. }\end{array}$ & $\begin{array}{l}\text { D.J. decide } \\
\text { conscientement } \\
\text { e viver em } \\
\text { hipocrisia. }\end{array}$ & \\
\hline$f$ & $\begin{array}{l}\text { A estátua } \\
\text { comparece ao } \\
\text { jantar e retribui } \\
\text { o convite. }\end{array}$ & & $\begin{array}{l}\text { Um espectro de } \\
\text { mulher pede o } \\
\text { arrependimento de } \\
\text { D. J. }\end{array}$ & $\begin{array}{l}\text { D. J. se recusa } \\
\text { a arrepender-se. }\end{array}$ & $\begin{array}{l}\text { O espectro se } \\
\text { transforma no } \\
\text { "tempo com a } \\
\text { foice na mão." }\end{array}$ \\
\hline $\mathrm{g}$ & & & & $\begin{array}{l}\text { D. J. não } \\
\text { comparece ao } \\
\text { jantar com a } \\
\text { estátua. }\end{array}$ & \\
\hline $\mathrm{h}$ & & $\begin{array}{l}\text { A estátua } \\
\text { encontra-o no } \\
\text { meio do } \\
\text { caminho. }\end{array}$ & $\begin{array}{l}\text { A estátua pede a } \\
\text { mão de D.J. }\end{array}$ & $\begin{array}{l}\text { D. J. estende } \\
\text { sua mão à } \\
\text { estátua. }\end{array}$ & \\
\hline$\overline{\mathrm{i}}$ & $\begin{array}{l}\text { A estátua leva } \\
\text { D. J. para o } \\
\text { inferno. }\end{array}$ & $\begin{array}{l}\text { Leporelo } \\
\text { anuncia que } \\
\text { todos ficaram } \\
\text { aliviados com a } \\
\text { morte de D.J. }\end{array}$ & & & \\
\hline
\end{tabular}

R. Inter. Interdisc. INTERthesis, Florianópolis, v.11, n.2, p.72-95, Jul-Dez. 2014

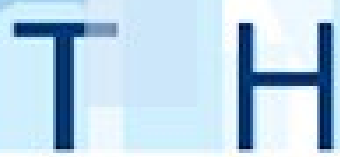


Don Juan é um mito sobre a lógica circular de causa e efeito aplicada à sexualidade humana. A análise estrutural da obra de Molina revela que não só o protagonista, como quis Molière, mas todos os personagens têm uma trajetória marcada pelo reflexo de seus desejos e atitudes.

Como se pode ler na tabela 1, Isabela aproveita a pouca luz para encontrarse com Otávio e é burlada por outro homem, na escuridão. Otávio reclama diretamente ao rei o seu prejuízo e é recompensado com terras e uma nova esposa, Tisbea, que renega o amor de Anfriso por ser pobre, se interessa por um nobre e é por ele burlada. Ana, que está prometida para alguém, marca um encontro com Mota e acaba burlada por outro. Mota aceita apostar o seu encontro e é enganado na aposta. Gonçalo tenta matar Don Juan pela honra de sua filha, honra que ela mesma não respeitou, e acaba morto por Don Juan que não chegou a desonrá-la. Batrício acredita na palavra do nobre, que era mentiroso, e desacredita a honestidade de sua esposa, que era honesta. Aminta, que também acredita na mentira de Don Juan, sentindo-se enganada por seu pai e por Batrício, acaba sendo burlada por aquele, sendo que os últimos não a enganaram.

Don Juan é o único personagem que tarda a receber de volta suas atitudes e desejos, porque ele ergue suas burlas em cima das brechas abertas pelos outros personagens. Nas três primeiras burlas, ele é beneficiado pelas condições criadas por outrem, até que, para burlar Aminta (Gd), sabendo que está mentindo para ambos os noivos, ele pede "que um homem morto lhe dê a morte se estiver mentindo" (MOLINA, 2004, p. 211). Logo depois, ele se depara com a estátua de Gonçalo.

A relação de Don Juan com a estátua reproduz a lógica circular de causa e efeito presente em todo o enredo. Ele convida a estátua para jantar justamente por pressupor que ela não pode aceitar, mas a estátua comparece. Na primeira versão, a estátua devolve o convite e Don Juan aceita. Durante o jantar, a estátua pede a mão de Don Juan, tal como ele fazia em suas burlas. Don Juan entrega a mão e por ela é puxado para o inferno. Na segunda versão, Don Juan não comparece ao jantar e a estátua vai até ele cobrar o encontro. A estátua pede que ele se arrependa, mas ele se recusa. A estátua pede a sua mão, ele dá a mão e o inferno vem buscá-lo.

Percebe-se que o que move a estória é uma espécie de equilíbrio perdido, o qual deve ser restaurado. Quando optamos por uma leitura sincrônica, 
acompanhando coluna a coluna (tabela 1), fica evidente a estrutura - Atitude burlesca (A); Reivindicação da honra (B); Fuga (C); Advertência (D e E). Essa relação só é resolvida na última linha, onde o Burlador é burlado e a ordem se restabelece. Lendo-se os acontecimentos de trás para frente, observamos que a última cena é o reequilíbrio de um sistema de casamento e alianças sociais, sendo que o desequilíbrio tem início já na primeira cena, com a atitude burlesca de Don Juan. Lendo-se as cenas da coluna $A$, de cima para baixo, temos a mesma relação: burlou e matou, foi burlado e morto, ou, de baixo para cima, foi morto e burlado, assim como matou e burlou.

O desassossego causado por Don Juan refere-se a um desequilíbrio no sistema de casamento e de relações sexuais consentidas. Sua ação negativa é colocar-se sorrateiramente entre os casais, para receber o que não the fora direcionado.

A segunda versão (tabela 2) confirma esse mesmo desequilíbrio geral do sistema como a propulsão da estória. As sucessivas colunas revelam uma estrutura quase idêntica à primeira: Atitude $(A)$; Fuga $(B)$; Reivindicação da honra ou pedido de arrependimento (C); Nova atitude ou tentativa (D); Advertência (E). Analogamente, esse encadeamento só é quebrado quando Don Juan desce ao inferno. A diferença básica é que os outros personagens parecem não seguir a mesma linha da versão original. Aqui, a relação burlesca acontece efetivamente somente com uma única mulher, Elvira, mas a mesma lógica se repete com o credor, Sr. Domingos, e com a própria Estátua.

Existe ainda uma cena ligeiramente modificada nessa obra (Ad), que juntamente com outras (Defg), condensa a consciência e a intenção declarada do burlador. Esta parece ser a principal contribuição de Molière, a saber, tornar o personagem de um jovem inconsequente, que duvida do céu, um libertino convicto que, mesmo diante da prova divina, reafirma sua devassidão. Mantém-se a característica de Don Juan colocar-se entre as relações de outros personagens, todavia, com a diferença principal de que ele se coloca também entre aqueles e a religião, como é o caso da cena inicial em que sequestra Elvira de um convento ou quando um mendigo the pede uma esmola em nome de Deus e Don Juan tenta fazê-lo blasfemar, em troca da moeda, para que ele traia sua fé.

R. Inter. Interdisc. INTERthesis, Florianópolis, v.11, n.2, p.72-95, Jul-Dez. 2014
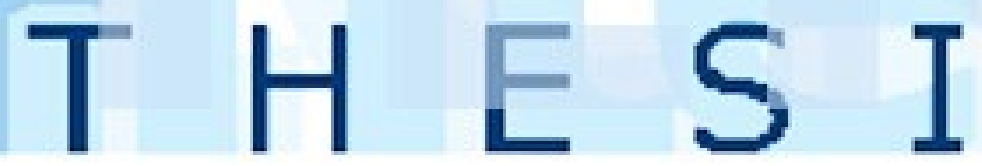
Fechando a análise para a saga do protagonista, observamos que Don Juan é igualmente um mito sobre o ímpeto do indivíduo em tentar triunfar sobre o sistema. Ao ser advertido sobre as punições vindouras, o personagem não só as ignora como as confronta. Enquanto, na primeira versão, essa atitude fica marcada pelo jargão Que tanto me fiais? - sua releitura imediata traz longos e portentosos discursos sobre a liberdade, o prazer e seu vício e sobre a hipocrisia, tão cara às altas classes. A grande ironia é que o tão anunciado castigo não é uma intervenção por vontade direta e consciente do além, mas aparece como uma encomenda do próprio burlador, uma vez que, ao matar Gonçalo, Don Juan eleva-o a uma grandeza contra a qual nada pode e, depois, ainda é ele mesmo que faz o irônico convite. Assim, notamos que mesmo a danação do personagem se funda num movimento de causa e efeito circular e não linear, como parece à primeira vista.

Há, ainda, inúmeros outros aspectos que engrandecem a natureza mítica da estória. Dentre esses, destacamos a interseção entre os planos divino e terreno e o caráter trágico e exemplar do enredo, o qual não só não poupa os personagens como leva às últimas consequências suas atitudes. Ressaltamos, também, os dilemas éticos, consagrado objeto dos mitos, que, nesse caso, são discutidos no âmbito da sexualidade, relacionamentos amorosos e do sistema de casamento.

As atualizações posteriores, como a versão de Mozart e Da Ponte (1787) e a de Lord Byron (1819-24), revelam que o sucesso e a ampla aceitação desse mito se devem muito menos ao seu nexo circular ou à questão do pagamento dos pecados cometidos do que aos dilemas éticos sobre os quais essa lógica é aplicada. É através do tema da sexualidade, do amor e dos relacionamentos amorosos que esse mito se eleva como um monumento subjetivo moderno.

Nesse sentido, quase todos os personagens da versão original partilham do mesmo ímpeto sexual que Don Juan. Isabela e Otávio mantinham ardentes relações às escuras. Tisbea já lança olhares libidinosos, enquanto Don Juan estava desacordado por conta do naufrágio. Ana e Mota tentam consumar seu antigo amor antes do casamento dela com outro. Por outro lado, o próprio Rei e Gonçalo negociam Ana, e Don Juan só consegue burlar Aminta porque diz a ela que já havia acertado com seu pai o casamento. Assim, é evidente que a substância onde essa lógica toda opera é a sexualidade.

R. Inter. Interdisc. INTERthesis, Florianópolis, v.11, n.2, p.72-95, Jul-Dez. 2014
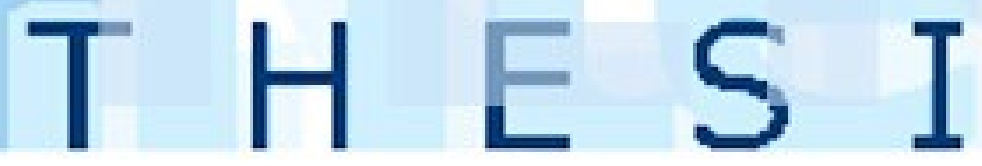
Há, contudo, um ponto que saltou à nossa leitura. Don Juan, de Molina, consegue a proeza de fazer aquela que seria sua futura esposa (cena Ea da tabela 1), traí-lo com ele mesmo! (cena Ac). No entanto, não é apenas isso, uma vez que, na mesma medida, ele acabou impedindo Ana de traí-lo com outro. Parece que, nesse momento, o personagem principal sofre um jogo de espelhos impressionante: ele consegue ocupar todos os arquétipos da obra, pois é o traidor, o traído e o salvador na mesma cena.

Seguindo a metodologia que indicamos, a análise estrutural nos proporcionou o entendimento das relações internas do mito. Essas análises mostraram-se bastante eficazes, visto que vivificaram os nexos do mito e seus temas principais. Resta-nos, agora, procurar a afinidade dessas com o contexto social em que fora produzido e que o consagrou.

Entendemos que existem dois principais aspectos do personagem que the garantem uma personalidade profunda, gerando a ilusão de ele poderia ter realmente existido. O primeiro deles, sem dúvida, é o narcisismo. Don Juan morre por seu narcisismo. Ele é o protótipo do individualismo moderno, pois pretende que o mundo esteja sempre ao seu serviço, ele não serve ao mundo. As regras e convenções que ele respeita são aquelas que o beneficiam. Don Juan não enxerga o outro, porque, de certa forma, vive fundido no outro, seu narcisismo sustenta a fantasia de que o mundo pode ser uma extensão de si.

Em extensão a isso, há o impetuoso desejo do personagem. Don Juan é muito obediente, poderíamos dizer submisso, à ordem de seu próprio desejo, encarnando a vontade onipotente do homem.

O segundo aspecto, que completa sua dinâmica psicológica, é a consciência que o próprio personagem apresenta de sua condição, especialmente na versão de Molière. Como uma volta sobre o seu próprio tema, o personagem faz discursos sobre si mesmo, defende sua postura, argumenta em seu próprio favor, a fim de fundamentar suas ações e desqualificar as convenções culturais que poderiam barrá-lo. Ou seja, Don Juan revela um esboço do que ficará consagrado na modernidade como a reflexividade do homem, já que se apresenta como um sujeito que pensa a si mesmo e traça as possibilidades de sua existência.

R. Inter. Interdisc. INTERthesis, Florianópolis, v.11, n.2, p.72-95, Jul-Dez. 2014
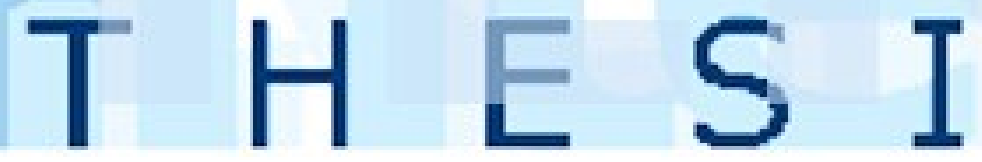


\section{DON JUAN, O MANEIRISMO E A CONTRARREFORMA}

O mito de Don Juan está estreitamente ligado ao movimento artístico que tomou forma a partir do colapso da Renascença: o chamado Maneirismo. Esse estilo, que se espalhou por toda a Europa, entre o início dos 1500 até meados dos 1600 , tem como principais características a liberdade de criação e o abuso do desequilíbrio (GONZÁLES, 2004; HAUSER, 2007).

Ambas as características se referem à contraposição dos maneiristas ao naturalismo idílico do renascimento. Assim, os temas maneiristas centram-se, não em um cultivo das virtudes divinas e da beleza proporcional de uma matemática sagrada, porém, antes, na exposição dos vícios e da assimetria do mundo e do próprio homem (HOCKE, 2005). Dessa maneira, se, por um lado, há o retorno às tragédias gregas nas quais o humano é um mero coadjuvante massacrado pela grandeza do destino, por outro, existe a reedição de um homem prometeico, cujo desejo deve governar a natureza.

A chave para entender a proposta desse movimento está na ideia de arte asiaticista dos gregos. Segundo Hocke (2005), devido à influência do oriente próximo, por volta do séc. $V$ a.C., fortalece-se o conceito de uma arte e filosofia diferentes da mimesis, ou seja, da mera reprodução da natureza visível em sua forma e semelhança. Baseado no phantastikon, há o cultivo do método intuitivo e a ampliação do critério de verdade e de beleza, considerando-se tudo aquilo que habita ou possa advir do pensamento. Muito similar ao método paranoico-crítico, de Salvador Dalí, "a suprema lei do asiaticismo assenta-se na arbitrariedade [...] mas trata-se de uma arbitrariedade que é, não raro, bem ponderada, até mesmo calculada" (HOCKE, 2005, p. 32).

Historicamente, a retomada maneirista desse estilo corresponde à crise de valores que assolava a Europa, naquela ocasião. Hauser (2007) escreve que os grandes dilemas da época giravam em torno das tentativas de conciliação entre o espiritual e o natural/mundano; entre a busca de salvação divina e a felicidade terrena, uma vez que "a validade da ética, os padrões artísticos de valor e a segurança científica foram lançados ao cadinho juntamente com o critério humano para a salvação" (HAUSER, 2007 p.18).

R. Inter. Interdisc. INTERthesis, Florianópolis, v.11, n.2, p.72-95, Jul-Dez. 2014
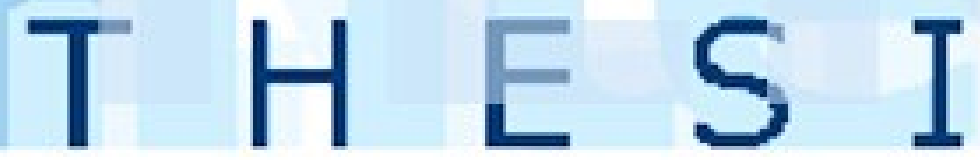
Os temas humanos que vamos encontrar sob essas diretrizes são extremamente psicológicos, encarnam questões viscerais, passeando por uma estrutura labiríntica de devaneios e emoções os quais intentam muito mais expor os dilemas da consciência do que resolvê-los, tal como Hamlet, o personagem maneirista por excelência, perdido na simulação de um enlouquecimento que realmente $o$ acometia.

Em um nível mais amplo, Watt (1997, p. 137) lembra-nos que os heróis contemporâneos a Don Juan, como Fausto e Don Quixote, acabam igualmente com uma emblemática punição, vendo-se isso "como uma amarga lição que a contrareforma tentou dar ao individualismo do Renascimento". O referido autor contribui com a ideia de que esses personagens vêm representar o sujeito individualizado ao qual o Renascimento deu origem e que se consolidou ao longo da modernidade até os dias de hoje.

Nesse quesito, Molina destaca-se de seus contemporâneos. Em comparação com esses, "a qualidade distintiva de Molina é a inaudita crueza analítica com a qual ele cria personagens e situações que envolvem as mais elementares contradições psicológicas e religiosas de suas vidas" (WATT, 1997, p. 101). O frade por trás de Tirso de Molina não deixou de imprimir em sua obra as grandes discussões religiosas de seu tempo.

Em sua obra dedicada à relação entre o pensamento de Molina e a Contrarreforma, Sullivan (1976) afirma que, pautado em sua respeitável formação teológica, Molina "tomou uma posição moderada no tocante à possibilidade de reconciliação da liberdade humana com a crença na eficácia da divina graça". Achava, por exemplo, "que o livre-arbítrio existia, mas fazia de Don Juan a prova mais contundente de que podemos ser vítimas de nossas próprias escolhas" (apud WATT, 1997, p. 136-137).

Ao mesmo tempo, Lilian Ribeiro (2007, p. 43) nos lembra que "o teatro foi diversas vezes utilizado com objetivos doutrinários". No caso do contexto em questão, a proximidade com o grande público, aliado à conjuntura contrarreformista, constitui o pano de fundo perfeito para que esse teatro se defina, igualmente, por sua finalidade pedagógica. A peça de Molina contém, claramente, uma lição de moral, promovendo uma "espécie de 'denuncia apologética' em que o intuito do autor é acusar quem se comporta como a personagem ao mesmo tempo efetuando

R. Inter. Interdisc. INTERthesis, Florianópolis, v.11, n.2, p.72-95, Jul-Dez. 2014
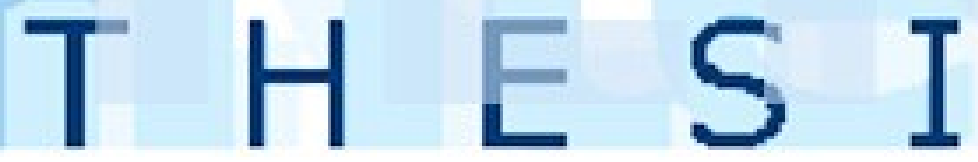
uma apologia da moralidade católica" (RIBEIRO, L. 2007, p. 21). Todavia, para isso, foi necessário trazer ao palco um exemplum que personificasse os valores moralmente condenáveis e desvelar sua personalidade adoecida, isto é, para realizar a pedagogia católica, foi imprescindível fazer psicologia profunda. É exatamente nesse jogo que Don Juan se eleva a mito. Uma vez que a ideologia contrarreformista e a intenção pedagógica da estória original foram filtradas pelo tempo, o que perdura é uma caricatura dos predicados humanos ali expostos.

Em diversas passagens, Hocke aponta uma certa continuidade entre o maneirismo e a modernidade. Para esse autor, tanto as qualidades quanto as desventuras que o homem moderno coloca em prática foram, antes, "testadas" na literatura maneirista. "Daí a espeleologia do maneirismo literário servir e auxiliar muito mais enquanto um saber moderno acerca do homem, do que como uma estética ultrapassada e erroneamente abstrata" (HOCKE, 200, p. 15).

Diante do exposto, parece-nos muito coerente tomar o personagem Don Juan e o seu drama como expressivos e reveladores dos fundamentos, dos alicerces do homem moderno. O script de Don Juan transporta-nos para a antessala da modernidade e suas produções subjetivas.

\section{DON JUAN E O ALVORECER DO HOMEM MODERNO}

O mito traz uma complexidade muito parecida com aquelas que vemos nos dias atuais. Tanto do ponto de vista externo, quanto interno, Don Juan encena o homem problemático, ou o homem em conflito.

Há dois grandes lemas que orientam a conduta do personagem. O primeiro seria "Esta noite hei de gozá-la", a irrupção do desejo sexual assim que ele avista uma mulher de que goste. O outro grande lema está contido frase "Que tanto me fiais!", a emblemática expressão com a qual o personagem desafia o Tempo e a Lei, ao responder toda vez que é advertido de uma possível punição. Desse modo, ilustra Renato Janine Ribeiro (1988), Don Juan levaria hipoteticamente no bolso um código de direito de um único artigo: "Este espanhol está autorizado a fazer o que Ihe der na telha" (p. 14).

O referido autor identifica em Don Juan a personificação da ruptura com o ideário religioso conferido à nobreza do Antigo Regime. Dentro dos parâmetros do

R. Inter. Interdisc. INTERthesis, Florianópolis, v.11, n.2, p.72-95, Jul-Dez. 2014
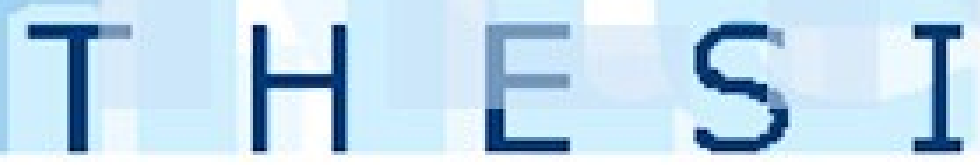
Antigo Regime, explica ele, o rei tem "o dever moral e religioso para com seus súditos. O seu prazer está sempre determinado pela missão moral que cumpre, pelo seu ofício claro de representante de Deus na Terra ou, pelo menos, em seu reino" (RIBEIRO, 1988, p. 18). Diferentemente disso, as empreitas do Burlador encerramse na satisfação de si mesmo, através de enganos e trapaças. Sua desenvoltura nessa área "faz com que ele seja inatingível para a justiça humana que, exercida pela mesma classe social à qual ele pertence, jamais consegue atingi-lo" (GONZÁLES, 2004, p. 27).

A aparente superioridade do personagem está também no fato de que ele desconhece o tempo; ele jamais se preocupa com o futuro. Don Juan busca a transcendência ao absoluto que promete a religião, no plano terrestre, não através da "boa conduta", mas de seu hedonismo. "D. Juan é a fuga à condição mortal no círculo mágico do delírio erótico - a ânsia do eterno presente" (RODRIGUES, 2005, p. 12).

Ao apresentar-se como "un hombre sin nombre", Don Juan está dizendo que não importa a posição social ocupada ou o que mais se poderia deduzir de sua identidade, mas, antes, importa a sua disposição carnal. Esse apelo se reforça quando, já descoberto, os guardas que falam em nome do Rei de Nápoles Ihe perguntam: "Quem és?" E Don Juan Ihes responde com outra pergunta, o que é bem característico dele, nessa obra: "E quem há de ser? Um homem, uma mulher" (MOLINA, 2004, p. 59).

Entendemos isso como a reafirmação de sua não identidade social, porém agora com um sentido mais aguçado ainda, ou seja, um homem e uma mulher fazendo coisas que homens e mulheres fazem.

Entretanto, o diferencial desse personagem é que não estamos diante de um pecador comum. Embora afeito aos prazeres da carne e à ridicularizarão dos valores "tradicionais", há em Don Juan uma consciência, e por vezes a justificação, de sua conduta. É evidente que não se trata de um simples homem refém de sua condição animal, mas de um homem dotado de reflexividade e retórica o suficiente para defender os seus ideais. Quando Cagarolão pergunta se ele pretende gozar Tisbea, Don Juan responde: "Mas se burlar é já meu hábito antigo, por que perguntas sabendo de minha condição?" (MOLINA, 2004, p. 119).

R. Inter. Interdisc. INTERthesis, Florianópolis, v.11, n.2, p.72-95, Jul-Dez. 2014
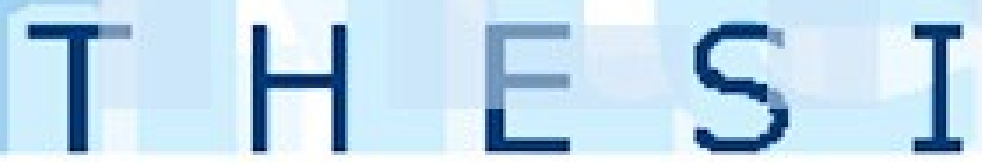
Se, em Molina, existia algum resquício de fé no personagem, Molière o coloca na vanguarda, como pode ser visualizado na passagem em que Leporelo questiona a fé de Don Juan e ele responde: "Em que eu acredito? [...] Eu acredito que dois e dois são quatro e que quatro e quatro são oito" (MOLIĖRE, 1997, p. 66).

Ainda que possa parecer genérico, vemos nessa afirmação a expressão do sujeito moderno. Don Juan parece ter saído da função alegórica de exemplum para ocupar o papel de representante efetivo do materialismo aristotélico, o qual logo se consagraria por todo o ocidente.

\section{CONSIDERAÇÕES FINAIS}

O fator que definitivamente conecta Don Juan à subjetividade moderna é a imagem consistente de uma "dinâmica psíquica" primordial. Esse mito é capaz de iluminar uma modalidade de relação com o mundo comum a todo ser humano até certo período do desenvolvimento mental. Toda sua trajetória é construída na articulação entre o desejo e a lei, elementos que, séculos mais tarde, a Psicanálise desvelaria como os componentes de uma relação fundamental do homem. À primeira vista, essa relação parece ser toda ocupada por agentes determinados: o desejante Don Juan satisfaz-se com as mulheres, passando por cima da lei, que retorna em forma de Estátua para ser aplicada. Contudo, a análise estrutural demonstra que só há um agente efetivo, uma causa a qual produz todas as consequências na obra: o desejo onipotente. Por essa perspectiva, ele é uma reedição da maldição de Narciso.

Por outro lado, é notável o posicionamento problemático de Don Juan, ao colocar-se entre os verdadeiros amantes, reivindicando para si uma paixão que não Ihe foi destinada. Outros elementos, como o parricídio, praticado não só concretamente, ao matar Gonzalo, mas reiterado diversas vezes no campo do simbólico, ao passar por cima das convenções sociais, ao entoar o seu jargão ou até mesmo quando se apresenta como não tendo um nome, revelam igualmente uma forte presença do mito de Édipo, tal como lido por Freud e pela Psicanálise.

Assim, Don Juan unifica em uma só persona as tragédias de Édipo e Narciso, colocando-as em dia com o livre arbítrio e a reflexividade do homem de nosso

R. Inter. Interdisc. INTERthesis, Florianópolis, v.11, n.2, p.72-95, Jul-Dez. 2014
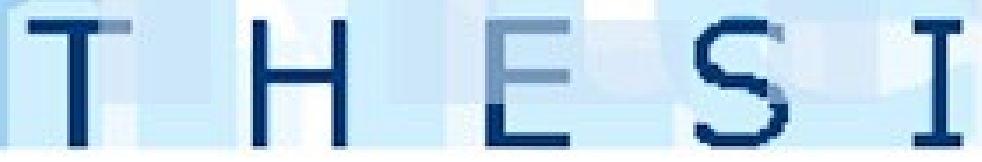
tempo. Tudo isso justaposto à mais visceral e universal experiência humana: a sexualidade.

R. Inter. Interdisc. INTERthesis, Florianópolis, v.11, n.2, p.72-95, Jul-Dez. 2014
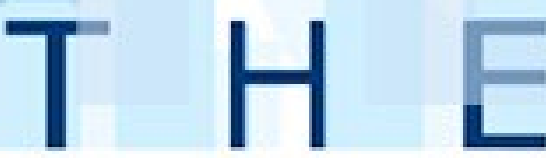


\section{AGRADECIMENTOS}

Gostaríamos de agradecer ao professor José Arthur Molina e ao professor Luis Carlos da Rocha, por seus apontamentos sobre este tema e pelos diálogos com nosso trabalho. Registramos também nosso especial agradecimento aos amigos Gabriel Kruger e Cesar Rey Xavier, por ouvir e contribuir com nossas reflexões e por nos ajudar a traçar os caminhos que resultaram neste artigo.

R. Inter. Interdisc. INTERthesis, Florianópolis, v.11, n.2, p.72-95, Jul-Dez. 2014
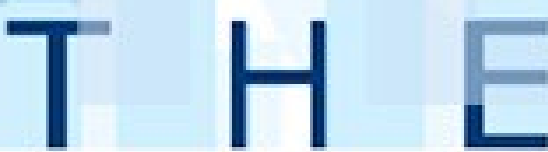


\title{
THE MYTH OF DON JUAN AND THE MODERN SUBJECTIVITY
}

\begin{abstract}
:
The legendary Don Juan character inhabits the popular imaginary with such a vibrancy of a myth, despite its slight recognition as such by the scientific literature. The purpose of this article is to verify if Don Juan's play can be understood, scientifically, as a modern myth, as well as understand its mythical nature and its relation to the modern man. A structural and historical analysis of the two first plays on Don Juan has guided us: the one written by Tirso de Molina in 1630, and the one by Molière, written in 1665 . The studies allow us to say that Don Juan is a typical modern myth, once it is constituted by narratives that expose a world looming under the signs of individualism, hedonism, arrogance and audacity forged under the appeals of sexual desire.
\end{abstract}

Keywords: Myth. Don Juan. Subjectivity. Modernity. Structuralism.

\section{EL MITO DE DON JUAN Y LA SUBJETIVIDAD MODERNA}

\section{Resumen:}

El personaje legendario de Don Juan vive en el imaginario popular con la intensidad de un mito a pesar de su escaso reconocimiento como tal en la literatura científica. El objetivo de este artículo consiste en verificar si Don Juan puede ser entendido como un mito moderno; comprender su naturaleza mítica y su relación con el hombre moderno. Buscamos orientarnos por un análisis estructuralista e histórica de dos obras literarias sobre Don Juan: una escrita por Tirso de Molina en 1630, y la de Moliere escrita en 1665. Los análisis sostienen que Don Juan es un mito moderno típico, porque está constituida por narrativas que pinzan, dan forma, concreción e inteligibilidad a un mundo y a un hombre naciente bajo los signos del individualismo, de la burla a la ley, del hedonismo, de la arrogancia y osadía, forjados a partir de la sexualidad.

Palabras clave: Mito. Don Juan. Subjetividad. Modernidad. Estructuralismo.

R. Inter. Interdisc. INTERthesis, Florianópolis, v.11, n.2, p.72-95, Jul-Dez. 2014 


\section{REFERÊNCIAS}

BEZERRA, P. V. Apontamentos acerca das vicissitudes da subjetividade no mito de Don Juan. 2011. 105f. Dissertação (Mestrado em Psicologia) - UNESP, Assis, 2011.

CASSIRER, E. Ensaio sobre o Homem: introdução a uma filosofia da cultura humana. São Paulo: Martins Fontes, 2005.

CASSIRER, E. Linguagem e Mito. São Paulo: Perspectiva, 2003.

ELIADE, M. Mito e Realidade. São Paulo: Perspectiva, 2010.

GONZÁLES, M. M. Introdução. In: MOLINA, T. de. Don Juan: O Burlador de Sevilha e o Convidado de Pedra. Edição, Tradução, Apresentação e notas: Alex Cojorian. Introdução: Mário M. Gonzávez. 1. ed. bil. Brasília: Círculo de Brasília, 2004. p.1337.

HAUSER, A. Maneirismo: a crise da renascença e o surgimento da arte moderna. São Paulo: Perspectiva, 2007.

HOCKE, G. R. Maneirismo na literatura. São Paulo: Perspectiva, 2011.

LÉVI-STRAUSS, C. Antropologia estrutural. São Paulo: Cosac Naify, 2008.

MOLIĖRE. Don Juan e o Convidado de Pedra. Tradução e adaptação: Millôr Fernandes. Porto Alegre: L\&PM, 1997.

MOLINA, T. de. Don Juan: O Burlador de Sevilha e o Convidado de Pedra. Edição, Tradução, Apresentação e notas: Alex Cojorian. Introdução: Mário M. Gonzávez. 1. ed. bil. Brasília: Circulo de Brasília, 2004.

RIBEIRO, R. J. (Org.). A sedução e suas máscaras: ensaios sobre Don Juan. São Paulo: Companhia das Letras, 1988.

RIBEIRO, L. S. S. Don Juan e a Construção de um mito em El Burlador de Sevilha. 2007. 79f. Dissertação (Mestrado em Letras) - USP, São Paulo, 2007. 
RICOEUR, P. Estrutura e Hermenêutica. In: LIMA, L. C. (Org). O estruturalismo de Lévi-Strauss. Petrópolis: Vozes, 1970 p. 24-53.

SAENZ-ALONSO, M. Don Juan y el donjuanismo. Madrid: Guadarrama, 1969.

VERNANT, Jean-Pierre. Mito e sociedade na Grécia Antiga. Rio de Janeiro: José Olímpio, 2010.

WATT, I. Mitos do individualismo moderno. Rio de Janeiro: J. Zahar, 1997.

\section{Artigo:}

Recebido em Maio de 2014

Aceito em Outubro de 2014

R. Inter. Interdisc. INTERthesis, Florianópolis, v.11, n.2, p.72-95, Jul-Dez. 2014 